\title{
Differential Electrochemicolor Imaging Using LSI-based Device for Simultaneous Detection of Multiple Analytes
}

\author{
Kosuke Ino, ${ }^{1 *}$ Takehiro Onodera, ${ }^{1}$ Yuji Nashimoto, ${ }^{1,2}$ and Hitoshi Shiku ${ }^{1 * *}$ \\ ${ }^{1}$ Graduate School of Engineering, Tohoku University, \\ 6-6-11 Aramaki-aza Aoba, Aoba-ku, Sendai 980-8579, Japan \\ ${ }^{2}$ Frontier Research Institute for Interdisciplinary Sciences, Tohoku University, \\ 6-3 Aramaki-aza Aoba, Aoba-ku, Sendai 980-8578, Japan
}

(Received June 27, 2018; accepted August 13, 2018)

Keywords: analytical electrochemistry, amperometry, LSI-based chip device, multiple detection system

Here, we present a novel imaging system that enables multiple reductants to be detected simultaneously in real time. Previously, we developed a novel electrochemical imaging system using an LSI-based amperometric device, for electrochemicolor imaging. The detection process consisted of applying half of the sensors at the oxidation potential to detect the target reductants, whereas the remaining sensors were applied at the reduction potential to monitor the target oxidants. This strategy enabled the simultaneous imaging of both targets in real time. However, the previous system required either oxidation or reduction potentials to be applied at individual sensors to distinguish between the redox signals of the oxidants and reductants, which limits its application. The present system solves this problem by differential electrochemical imaging to monitor two types of reductants. Detection is achieved by subtracting the electrochemical images acquired at a specified oxidation potential from those acquired at a different oxidation potential. As a demonstration, $p$-aminophenol (PAP) and $p$-aminophenyl phosphate (PAPP) were detected as the two target reductant species. Our experiments confirmed that the proposed differential electrochemicolor imaging system allows the diffusion of these two target reductant species to be visualized in real time. In the near future, the imaging system will be applied to cell analysis.

\section{Introduction}

Electrochemical imaging is a powerful analytical method for chemical mapping. Several kinds of electrode arrays have been developed for this purpose. ${ }^{(1-7)}$ For example, a large number of sensors can be incorporated into a small chip device by utilizing redox cyclingbased switching systems ${ }^{(1-3)}$ and integrated electrode arrays consisting of $\operatorname{droplet}^{(7)}$ and fluidic compartments. ${ }^{(4)}$ These electrode arrays have been utilized for bioanalysis. Recently, an LSI chip including a CCD and a CMOS sensor was also developed for electrochemical bioimaging. ${ }^{(8-15)}$ This chip found applications in the imaging of oligonucleotides ${ }^{(9,14)}$ and the release of neurotransmitters. ${ }^{(11)}$

\footnotetext{
*Corresponding author: e-mail: kosuke.ino@tohoku.ac.jp

**Corresponding author: e-mail: hitoshi.shiku.c3@tohoku.ac.jp

https://doi.org/10.18494/SAM.2019.2035
} 
In addition to these devices, we developed a CMOS-based amperometric device, which we named the Bio-LSI device. ${ }^{(16-20)}$ The amperometric device was applied to bioassays including cell analysis. For example, we successfully monitored the alkaline phosphatase (ALP) activity in embryonic stem (ES) cells to evaluate the differentiation levels of these cells. ${ }^{(20)}$ However, conventional electrochemical imaging can monitor only one type of target analyte at a constant potential. The detection of multiple analytes necessitates potential scanning to be used.

Bellin et al. reported square wave voltammetry (SWV) on a CMOS-based electrode array for imaging multiple metabolites in biofilms. ${ }^{(8)}$ However, the time resolution in SWV may be insufficient for rapid events such as those involving exocytosis. Therefore, it is necessary to develop an electrochemical device/system capable of rapid and multispecies imaging without the need for potential scanning.

We previously proposed a novel electrochemical imaging system that enables the simultaneous detection of multiple analytes, a technique known as electrochemicolor imaging. ${ }^{(21,22)}$ Electrochemicolor imaging using the Bio-LSI device applies half of the sensors at the oxidation potential to detect reductants. The other sensors are set to the reduction potential to monitor the oxidants. Because these potentials are applied in a checkered pattern, we can simultaneously acquire two electrochemical images of an entire area to show the oxidation and reduction currents in real time without potential scanning. In our previous studies, the electrochemicolor imaging system was used for the detection of enzymatic products (reductant) and dissolved oxygen (oxidant); we successfully evaluated both the ALP and respiration activities of ES cells ${ }^{(22)}$ and mesenchymal stem cells (MSCs). ${ }^{(21)}$ In addition, the release of dopamine (reductant) and the respiration activities of neuron-like cells were simultaneously imaged in real time. ${ }^{(22)}$ Thus, reductants can be distinguished from oxidants by applying oxidation and reduction potentials at individual sensors. However, this strategy cannot be used to distinguish between two types of reductants (or oxidants) by applying two different potentials, because both reductants are oxidized at one of the two potentials and it is difficult to distinguish between them.

The present study led us to propose a differential electrochemicolor imaging system to detect two types of reductants. This system has the capability to acquire two electrochemical images at two oxidation potentials to monitor two types of reductants. A differential electrochemical image is then prepared by subtracting one electrochemical image showing one type of reductant from the other electrochemical image showing both of the reductants to obtain an image showing the target reductant. In this study, as a demonstration, two types of reductants, $p$-aminophenol (PAP) and $p$-aminophenyl phosphate (PAPP), were monitored. In practice, this involved the introduction of a drop containing these reductants onto the sensing area to allow the diffusion of these two redox compounds to be simultaneously monitored in real time.

\section{Materials and Methods}

\subsection{Device fabrication}

The process of device fabrication was described in detail in our previous papers. ${ }^{(18,19)}$ Briefly, $400 \mathrm{Pt}$ working electrodes were prepared at a pitch of $250 \mu \mathrm{m}$ (Fig. 1). SU-8 


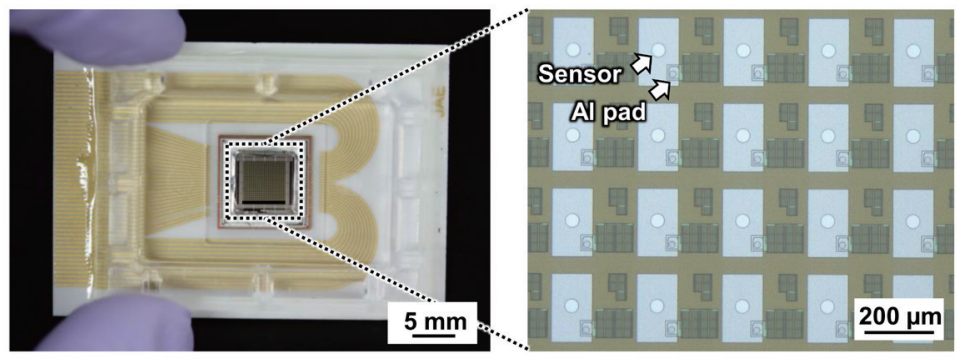

(a)

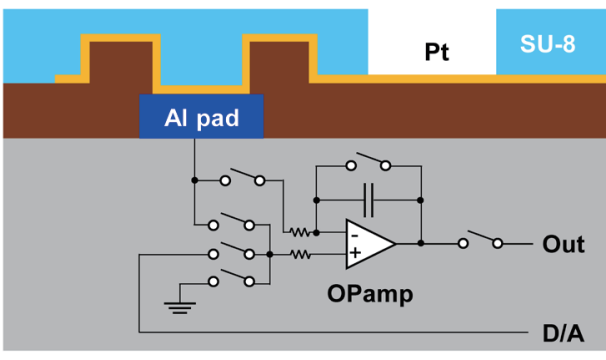

(b)

Fig. 1. (Color online) (a) Optical images of the device containing $400 \mathrm{Pt}$ individual working electrodes. (b) Schematic cross section of the sensor.

microwells (40 $\mu \mathrm{m}$ in diameter and $5 \mu \mathrm{m}$ in depth) were prepared on the electrodes to form a Pt disk electrode with a diameter of $40 \mu \mathrm{m}$ at the bottom of each of the microwells. The device was connected to a Bio-LSI system for electrochemical detection. ${ }^{(18)}$ Figure 1(b) shows the schematic cross section of the sensor. The device is based on CMOS technology, and each sensor contains an operational amplifier with a switched-capacitor-type $I-V$ converter to amplify the in-pixel signal for amperometric detection. ${ }^{(18)}$ In the Bio-LSI system, a potentiostat or potentiometer mode can be selected for each electrode, although the potentiometer mode was not used in this study.

\subsection{Detection system}

The signal read-out process was described in our previous paper. ${ }^{(18)}$ Briefly, the electric signals at $20 \times 20$ sensor points are sequentially read out. The process was controlled by a program written in LabVIEW (National Instruments, USA). A sample solution was introduced into the sensing area surrounded by the frame on the device. Then, $\mathrm{Ag} / \mathrm{AgCl}$ (sat. $\mathrm{KCl}$ ) reference and Pt counter electrodes were inserted into the solution. Cyclic voltammetry (CV) and amperometry were performed to obtain an electrochemical image every $24 \mathrm{~ms}$. As a demonstration, PAP (Wako Pure Chemical Industries Ltd., Japan) and PAPP (LKT Laboratories, USA) were detected.

\subsection{CV of PAP and PAPP}

$\mathrm{CV}$ was conducted by introducing $1 \mathrm{~mL}$ samples of phosphate-buffered saline (PBS; Wako Pure Chemical Industries Ltd.) containing 0.5 mM PAP and/or PAPP into the device. A control experiment was carried out using PBS without redox compounds. The scan rate was $20 \mathrm{mV} / \mathrm{s}$. The potential at all sensor electrodes was scanned from 0 to $0.7 \mathrm{~V}$.

\subsection{Electrochemicolor imaging}

The electrochemicolor imaging process is explained graphically in Fig. 2. As shown in Fig. 2(a), a potential of either 0.4 or $0.7 \mathrm{~V}$ was applied at individual sensors in a checkered 


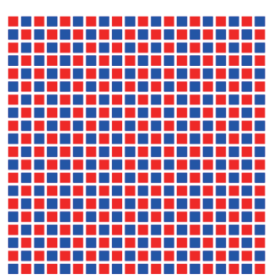

0.4 V for oxidation of PAP

0.7 V for oxidation of PAP and PAPP

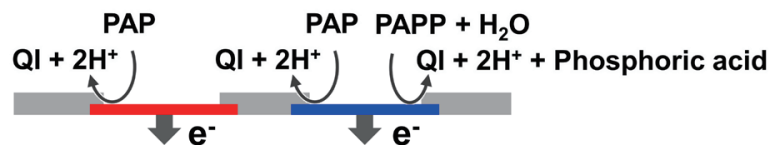

(a)
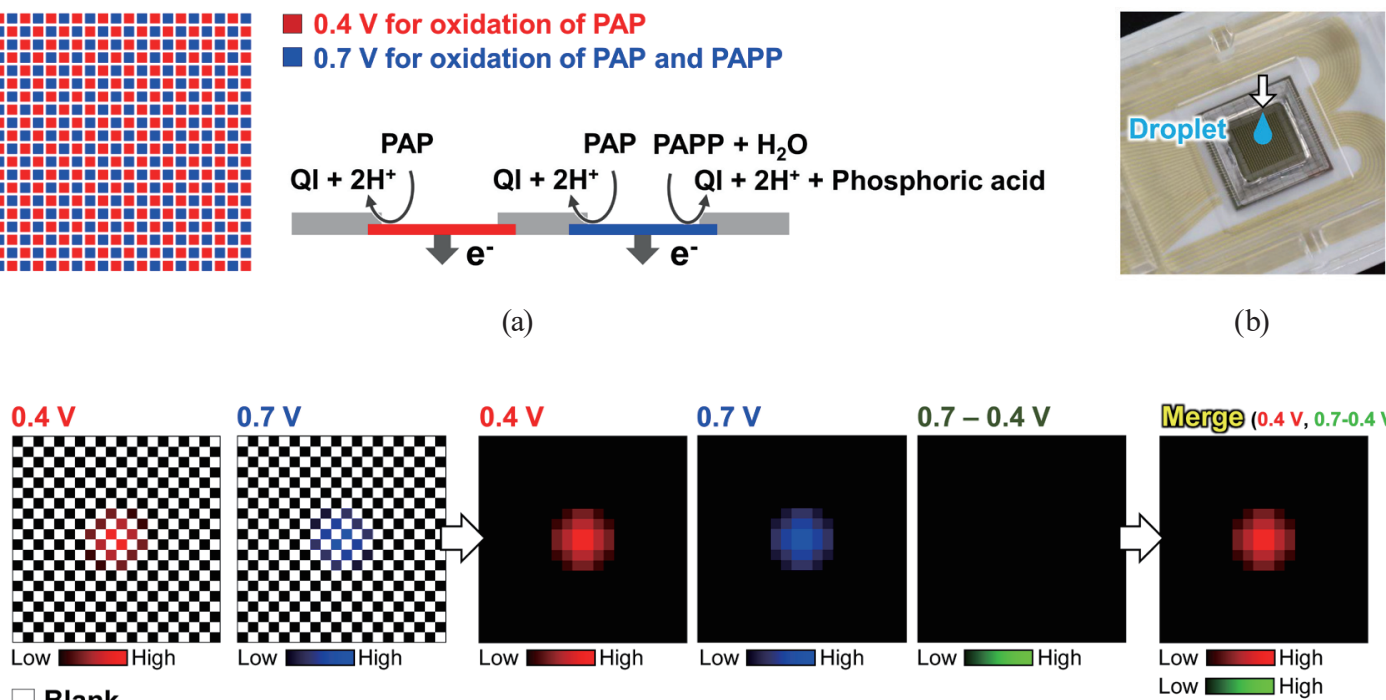

(b)

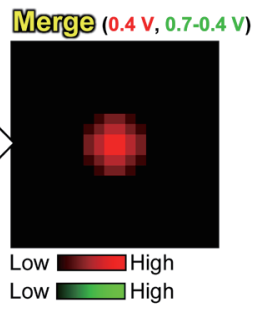

Low $\square$ High

(c)

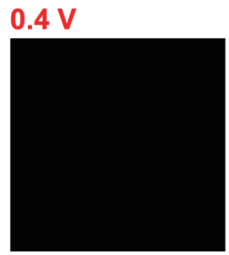

Low $\square$ High

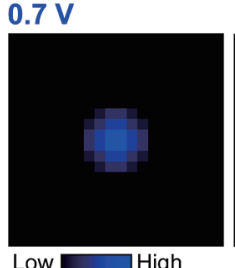

Low High
$0.7-0.4 \mathrm{~V}$

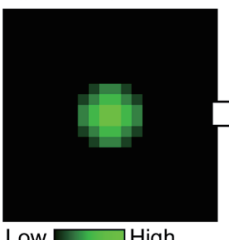

Low $\square$ High

(d)

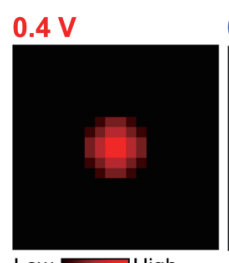

$0.7 \mathrm{~V}$
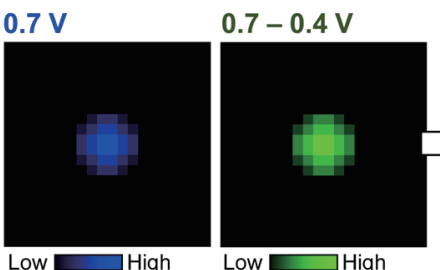

Low High

d)

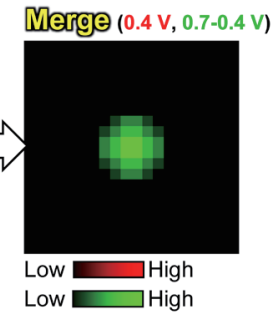


pattern. PAP was oxidized at $0.4 \mathrm{~V}$, and both PAP and PAPP were oxidized at $0.7 \mathrm{~V}$. As a demonstration, a $3 \mu \mathrm{L}$ droplet containing PAP and/or PAPP was introduced into $1 \mathrm{~mL}$ PBS on the device [Fig. 2(b)], and the diffusion of the redox compounds was monitored. After the introduction of the droplet, two electrochemical images consisting of redox signals at 0.4 and $0.7 \mathrm{~V}$ were acquired [Fig. 2(c)]. The electrochemical images at 0.4 and $0.7 \mathrm{~V}$ show the oxidation of PAP and that of both PAP and PAPP, respectively. Because electrochemical signals at half of the sensors are used for each electrochemical image, these electrochemical images consist of 200 electrochemical signals and 200 blanks, resulting in checkered images. The blanks are filled using a mathematical approach based on the biharmonic spline in LabVIEW to complete the electrochemical images consisting of 400 electrochemical signals [Fig. 2(c)]. A differential electrochemical image showing the oxidation currents of PAPP is obtained by subtracting the electrochemical image acquired at $0.4 \mathrm{~V}$ from that at $0.7 \mathrm{~V}$ [Fig. 2(d)]. As an optional process, the two electrochemical images at 0.4 and $0.7-0.4 \mathrm{~V}$ are merged to create an electrochemicolor image consisting of two signal scales [Figs. 2(c)-2(e)]. The introduction of a droplet containing both $0.5 \mathrm{mM}$ PAP and $0.5 \mathrm{mM}$ PAPP makes it possible to visualize two oxidation currents in a single image [Fig. 2(e)].

\subsection{Detection of various concentrations of PAP and PAPP}

As shown in Fig. 2(a), a potential of either 0.4 or $0.7 \mathrm{~V}$ was applied at individual sensors in a checkered pattern. First, $1 \mathrm{~mL}$ of PBS was introduced, and chronoamperometry was started. Then, a high-concentration solution of either PAP or PAPP was added to the PBS, and the solution was rapidly mixed. The same process was repeated to monitor various concentrations of PAP $(0,0.1,0.2,0.3$, and $0.4 \mathrm{mM})$ and $\operatorname{PAPP}(0,0.1$, and $0.2 \mathrm{mM})$.

\section{Results and Discussion}

Figure 3(a) shows the CV results of PAP and PAPP. According to the results, $0.4 \mathrm{~V}$ was sufficient to oxidize only PAP, whereas $0.7 \mathrm{~V}$ was sufficient to oxidize both PAP and PAPP. As microelectrodes were used, the oxidation current of PAP at $0.4 \mathrm{~V}$ was similar to that at $0.7 \mathrm{~V}$. Therefore, the electrochemical image at $0.4 \mathrm{~V}$ can be utilized to visualize PAP, because PAPP does not react at $0.4 \mathrm{~V}$. In contrast, to visualize PAPP, the differential electrochemical image at $0.7-0.4 \mathrm{~V}$ is suitable, because the same currents were obtained from PAP at 0.4 and $0.7 \mathrm{~V}$. Therefore, we selected 0.4 and $0.7 \mathrm{~V}$ for the electrochemicolor imaging of PAP and PAPP. Figure 3(b) shows the cyclic voltammogram of the solution containing PAP and PAPP. The currents show the sum of the currents of PAP and PAPP in Fig. 3(a), indicating that PAP (or PAPP) did not interfere with the detection of the other. Figure 3(c) shows the difference between the cyclic voltammogram in Fig. 3(b) and that in Fig. 3(a). The subtracted cyclic voltammograms of "PAP + PAPP" - "PAPP" and "PAP + PAPP" - "PAP" are similar to the cyclic voltammograms of only "PAP" and only "PAPP", respectively. These results indicate that the concept of differential electrochemicolor imaging can function satisfactorily. 


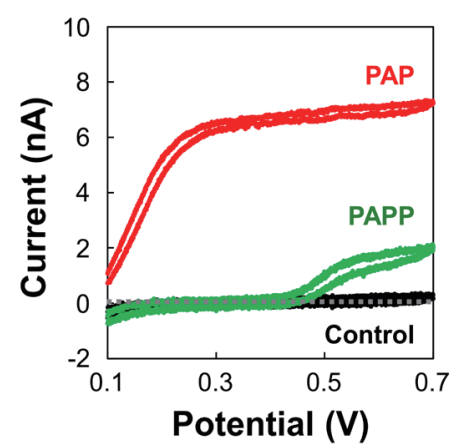

(a)

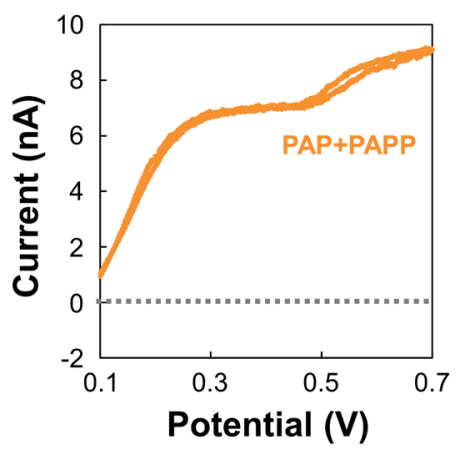

(b)

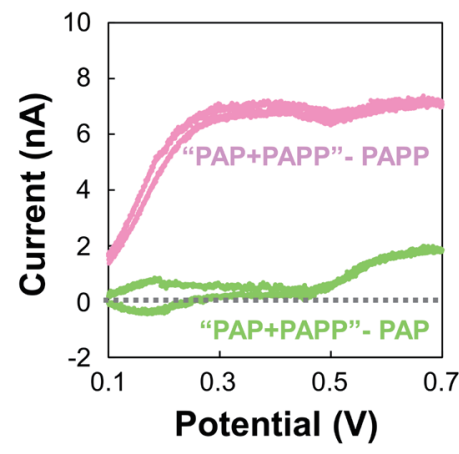

(c)

Fig. 3. (Color online) Cyclic voltammograms. (a) $0.5 \mathrm{mM}$ PAP, $0.5 \mathrm{mM}$ PAPP, or control. PBS without redox compounds was used as control. (b) $0.5 \mathrm{mM}$ PAP and $0.5 \mathrm{mM}$ PAPP. (c) Subtracted cyclic voltammograms. The currents in (b) were subtracted from those in (a). The scan rate was $20 \mathrm{mV} / \mathrm{s}$.

Next, we introduced a droplet containing PAP and/or PAPP and monitored its diffusion. When the droplet containing PAP was introduced, the redox signals of PAP were acquired at both 0.4 and $0.7 \mathrm{~V}$ [Fig. 4(a)], which is in agreement with the results in Fig. 3. The electrochemical image followed the position of the droplet. The differential electrochemical image at $0.7-0.4 \mathrm{~V}$ shows no current, because the current from PAP at $0.7 \mathrm{~V}$ was similar to that at $0.4 \mathrm{~V}$.

Next, a droplet containing PAPP was examined. The redox signals were detected at only 0.7 V [Fig. 4(b)], which also agrees with those in Fig. 3. Because the electrochemical image at 0.4 $\mathrm{V}$ showed no redox current, the differential electrochemical image at 0.7-0.4 $\mathrm{V}$ was similar to that at $0.7 \mathrm{~V}$. Figures $4(\mathrm{a})$ and $4(\mathrm{~b})$ indicate that the electrochemical image at $0.4 \mathrm{~V}$ shows the oxidation currents of only PAP, and the differential electrochemical image at $0.7-0.4 \mathrm{~V}$ shows the oxidation currents of only PAPP.

When a droplet containing both PAP and PAPP was tested, the electrochemical signals from the droplet appeared at both 0.4 and $0.7 \mathrm{~V}$ [Fig. 4(c)]. The intensities of the redox signals at 0.7 $\mathrm{V}$ were higher than those at $0.4 \mathrm{~V}$, because both PAP and PAPP were oxidized at $0.7 \mathrm{~V}$. Because PAPP is contained in one droplet, the redox signals appeared in the differential electrochemical image at $0.7-0.4 \mathrm{~V}$, although the differential electrochemical image at $0.7-0.4 \mathrm{~V}$ was slightly unclear compared with the other images. Thus, the two types of reductants were successfully imaged. The current generated at the electrodes was converted into images containing multiple colors, for example, red and green to indicate the oxidation currents of PAP and PAPP, respectively. The electrochemicolor imaging, as an optional process, consisted of two oxidation currents for PAP and PAPP. Therefore, the detection of both PAP and PAPP produced a yellow image.

The time resolution of the imaging was $24 \mathrm{~ms}$; thus, the diffusion of the redox compounds was successfully imaged in real time (Fig. 5). The electrochemical signals appeared soon after the introduction of the droplet and disappeared within $10 \mathrm{~s}$, indicating that the redox compounds rapidly diffused owing to the flow. This indicates that phenomena that occur rapidly can be imaged by differential electrochemicolor imaging. In the near future, this imaging technique 


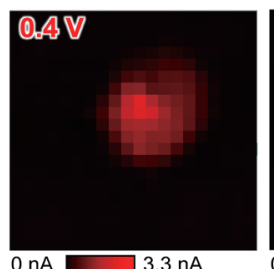

$0 \mathrm{nA} \longrightarrow 3.3 \mathrm{nA}$

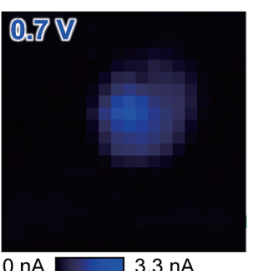

$0 \mathrm{nA}=3.3 \mathrm{nA}$

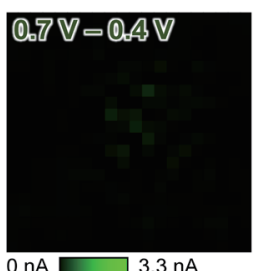

(a)

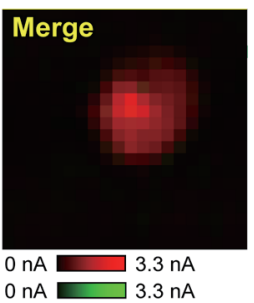

$3.3 \mathrm{nA}$
$\mathrm{nAA}$
$3.3 \mathrm{nA}$
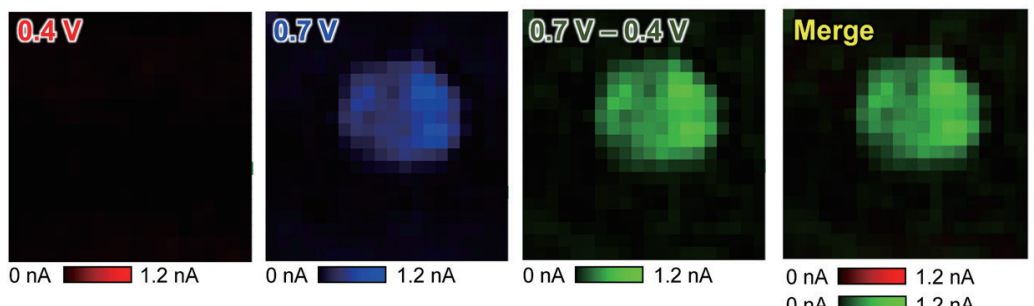

(b)
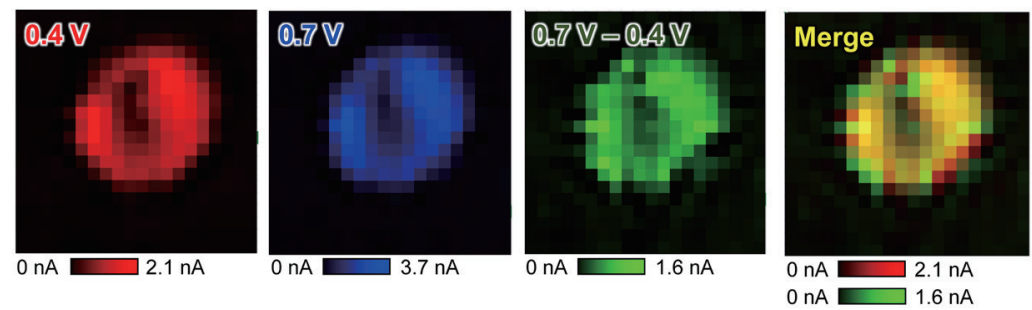

(c)

Fig. 4. (Color online) Differential electrochemicolor imaging of droplets of PBS containing PAP and/or PAPP. A droplet containing the redox compounds in PBS was introduced onto the device, to which 0.4 and $0.7 \mathrm{~V}$ were applied at the electrodes in checkered patterns. Electrochemicolor images immediately after the introduction of a droplet of (a) PAP, (b) PAPP, or PAPP and (c) PAP. The concentrations of PAP and PAPP were $0.5 \mathrm{mM}$. The red and green images indicate the oxidation currents of PAP and PAPP.
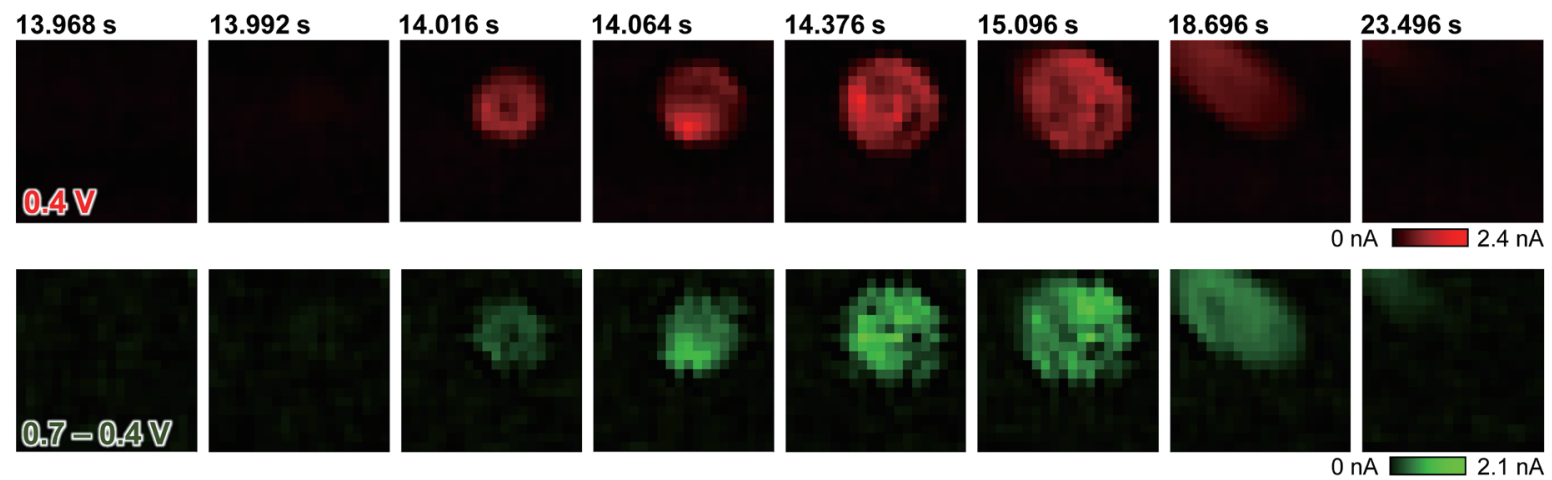

Fig. 5. (Color online) Differential electrochemicolor imaging of droplets of PBS containing PAP and PAPP in real time. Time resolution: $24 \mathrm{~ms}$. Selected images are displayed because of space limitations. The concentrations of PAP and PAPP were $0.5 \mathrm{mM}$. 
will be used to monitor the release of dopamine from cells in the presence of ascorbic acid without potential scanning, e.g., by fast-scan voltammetry, although the interaction between dopamine and ascorbic acid during electrochemical detection would have to be carefully investigated. Previously, electrode arrays were applied to three-dimensional tissue organs; hence, ${ }^{(23-26)}$ we also aim to investigate the current system for possible application in this regard, such as in organs-on-a-chip.

Figure 6(a) shows amperograms for various concentrations of PAP and PAPP. When the concentration of PAP was changed from 0 to $0.1 \mathrm{mM}$, the oxidation currents at $0.4 \mathrm{~V}$ increased from 0 to $1.3 \mathrm{nA}$. When the concentration increased from 0.1 to $0.2 \mathrm{mM}$, the current increased from 1.3 to $2.5 \mathrm{nA}$. As shown in Fig. 6(b), the current was proportional to the PAP concentration, indicating that the method is quantitative. The current at $0.4 \mathrm{~V}$ was similar to that at $0.7 \mathrm{~V}$. The result agrees with that in Fig. 3. In the presence of $0.2 \mathrm{mM}$ PAPP, when the PAP concentration increased from 0.2 to $0.3 \mathrm{mM}$, the current increased from 2.5 to $3.7 \mathrm{nA}$. The slope in the presence of PAPP was $12 \mathrm{nA} / \mathrm{mM}$, which was similar to that in the absence of PAPP $(13 \mathrm{nA} / \mathrm{mM})$, indicating that PAP was quantitatively detected even though PAPP was mixed. Figure 6(c) shows that current at $0.7-0.4 \mathrm{~V}$ was generally proportional to the PAPP concertation. Thus, the method is able to quantitatively detect PAP and PAPP.

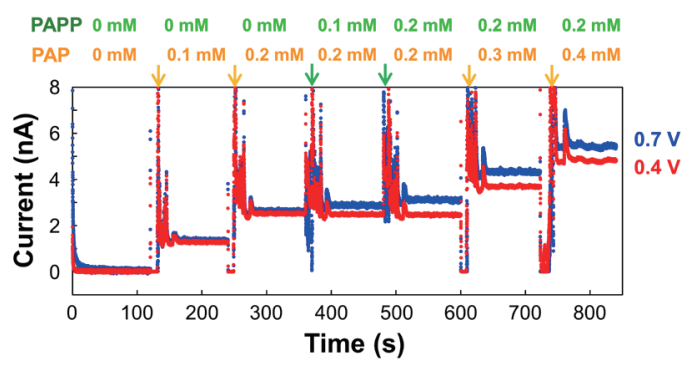

(a)

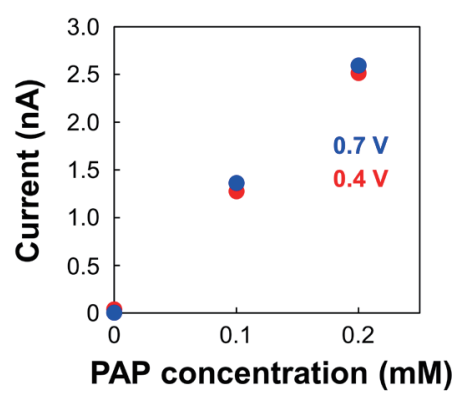

(b)
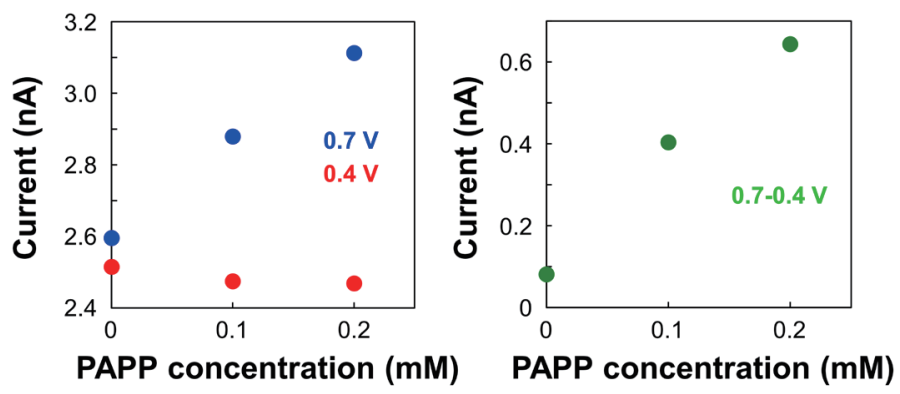

(c)

Fig. 6. (Color online) Detection of various concentrations of PAP and PAPP. (a) Amperograms from the sensors at 0.4 and $0.7 \mathrm{~V}$. Orange and green arrows indicate the time when a solution of PAP or PAPP was added. The concentration was adjusted by rapidly mixing the solution (PAP: $0,0.1,0.2,0.3$, or $0.4 \mathrm{mM}$, PAPP: $0,0.1$, or 0.2 $\mathrm{mM}$ ). (b) Current vs PAP concentration from the sensors at 0.4 or $0.7 \mathrm{~V}$. (c) Current vs PAPP concentration from the sensors at 0.4 or $0.7 \mathrm{~V}$ (left). The graph on the right shows the difference between the currents at 0.7 and $0.4 \mathrm{~V}$. 


\section{Conclusions}

Two reductants were successfully detected by differential electrochemicolor imaging. In the research presented in this paper, PAP and PAPP were successfully monitored in real time as a demonstration. In the near future, the detection system will be utilized for bioassays including cell analysis.

\section{Acknowledgments}

This work was supported by a Grant-in-Aid for Scientific Research (A) (No. 16H02280), Grants-in-Aid for Scientific Research (B) (Nos. 15H03542, 18H01840, and 18H01999), a Grantin-Aid for Challenging Exploratory Research (No. 16K14012), and a Grant-in-Aid for Young Scientists (A) (No. 15H05415) from the Japan Society for the Promotion of Science (JSPS). This work was also supported by the Asahi Glass Foundation and Program for Creation of Interdisciplinary Research from Frontier Research Institute for Interdisciplinary Sciences, Tohoku University. The authors thank Professor Tomokazu Matsue (Tohoku University) for his assistance with the experimental equipment. The authors thank Dr. Astushi Suda and Ryota Kunikata (Japan Aviation Electronics Industry) for their assistance with the fabrication of the chip devices. The authors thank Kimiko Takahashi for her assistance with the experiments.

\section{References}

1 K. Ino, Y. Kanno, T. Nishijo, H. Komaki, Y. Yamada, S. Yoshida, Y. Takahashi, H. Shiku, and T. Matsue: Anal. Chem. 86 (2014) 4016. https://doi.org/10.1021/ac500435d

2 K. Ino, T. Nishijo, T. Arai, Y. Kanno, Y. Takahashi, H. Shiku, and T. Matsue: Angew. Chem. Int. Ed. 51 (2012) 6648. https://doi.org/10.1002/anie.201201602

3 B. Wolfrum, E. Katelhon, A. Yakushenko, K. J. Krause, N. Adly, M. Huske, and P. Rinklin: Acc. Chem. Res. 49 (2016) 2031. https://doi.org/10.1021/acs.accounts.6b00333

4 J. Yao, X. A. Liu, and K. D. Gillis: Anal. Methods 7 (2015) 5760. https://doi.org/10.1039/c5ay00229j

5 K. Hayashi, T. Horiuchi, R. Kurita, K. Torimitsu, and O. Niwa: Biosens. Bioelectron. 15 (2000) 523. https:// doi.org/10.1016/S0956-5663(00)00103-2

6 N. Kasai, Y. Jimbo, and K. Torimitsu: Anal. Sci. 18 (2002) 1325. https://doi.org/10.2116/analsci.18.1325

7 H. Zhang, T. Oellers, W. Feng, T. Abdulazim, E. N. Saw, A. Ludwig, P. A. Levkin, and N. Plumere: Anal. Chem. 89 (2017) 5832. https://doi.org/10.1021/acs.analchem.7b00008

8 D. L. Bellin, H. Sakhtah, J. K. Rosenstein, P. M. Levine, J. Thimot, K. Emmett, L. E. P. Dietrich, and K. L. Shepard: Nat. Commun. 5 (2014) 3256. https://doi.org/10.1038/ncomms4256

9 A. L. Ghindilis, M. W. Smith, K. R. Schwarzkopf, K. M. Roth, K. Peyvan, S. B. Munro, M. J. Lodes, A. G. Stover, K. Bernards, K. Dill, and A. McShea: Biosens. Bioelectron. 22 (2007) 1853. https://doi.org/10.1016/ j.bios.2006.06.024

10 T. Hattori, H. Satou, K. Tokunaga, R. Kato, and K. Sawada: Sens. Mater. 27 (2015) 1023. https://doi. org/10.18494/SAM.2015.1139

11 B. N. Kim, A. D. Herbst, S. J. Kim, B. A. Minch, and M. Lindau: Biosens. Bioelectron. 41 (2013) 736. https:// doi.org/10.1016/j.bios.2012.09.058

12 T. Kuno, K. Niitsu, and K. Nakazato: Jpn. J. Appl. Phys. 53 (2014) https://doi.org/10.7567/jjap.53.04el01

13 C. Laborde, F. Pittino, H. A. Verhoeven, S. G. Lemay, L. Selmi, M. A. Jongsma, and F. P. Widdershoven: Nat. Nanotechnol. 10 (2015) 791. https://doi.org/10.1038/nnano.2015.163

14 Y. Maruyama, S. Terao, and K. Sawada: Biosens. Bioelectron. 24 (2009) 3108. https://doi.org/10.1016/ j.bios.2009.03.031

15 J. B. Wydallis, R. M. Feeny, W. Wilson, T. Kern, T. Chen, S. Tobet, M. M. Reynolds, and C. S. Henry: Lab Chip 15 (2015) 4075. https://doi.org/10.1039/c5lc00778j 
16 H. Abe, K. Ino, C. Z. Li, Y. Kanno, K. Y. Inoue, A. Suda, R. Kunikata, M. Matsudaira, Y. Takahashi, H. Shiku, and T. Matsue: Anal. Chem. 87 (2015) 6364. https://doi.org/10.1021/acs.analchem.5b01307

17 K. Ino, Y. Kanno, K. Y. Inoue, A. Suda, R. Kunikata, M. Matsudaira, H. Shiku, and T. Matsue: Angew. Chem. Int. Ed. 56 (2017) 6818. https://doi.org/10.1002/anie.201701541

18 K. Y. Inoue, M. Matsudaira, M. Nakano, K. Ino, C. Sakamoto, Y. Kanno, R. Kubo, R. Kunikata, A. Kira, A. Suda, R. Tsurumi, T. Shioya, S. Yoshida, M. Muroyama, T. Ishikawa, H. Shiku, S. Satoh, M. Esashi, and T. Matsue: Lab Chip 15 (2015) 848. https://doi.org/10.1039/c4lc01099j

19 Y. Kanno, K. Ino, C. Sakamoto, K. Y. Inoue, M. Matsudaira, A. Suda, R. Kunikata, T. Ishikawa, H. Abe, H. Shiku, and T. Matsue: Biosens. Bioelectron. 77 (2016) 709. https://doi.org/10.1016/j.bios.2015.10.021

20 M. Sen, K. Ino, K. Y. Inoue, T. Arai, T. Nishijo, A. Suda, R. Kunikata, H. Shiku, and T. Matsue: Biosens. Bioelectron. 48 (2013) 12. https://doi.org/10.1016/j.bios.2013.03.069

21 K. Ino, T. Onodera, Y. Kanno, A. Suda, R. Kunikata, T. Matsue, and H. Shiku: Electrochim. Acta 268 (2018) 554. https://doi.org/10.1016/j.electacta.2018.02.094

22 Y. Kanno, K. Ino, H. Abe, C. Sakamoto, T. Onodera, K. Y. Inoue, A. Suda, R. Kunikata, M. Matsudaira, H. Shiku, and T. Matsue: Anal. Chem. 89 (2017) 12778. https://doi.org/10.1021/acs.analchem.7b03042

23 K. Ino, M. Sen, H. Shiku, and T. Matsue: Analyst 142 (2017) 4343. https://doi.org/10.1039/c7an01442b

24 K. Ino, H. Shiku, and T. Matsue: Curr. Opin. Electrochem. 5 (2017) 146. https://doi.org/10.1016/ j.coelec.2017.08.004

25 T.-E Lin, S. Rapino, H. H. Girault, and A. Lesch: Chem. Sci. 9 (2018) 4546. https://doi.org/10.1039/ $\mathrm{C} 8 \mathrm{SC} 01035 \mathrm{H}$

26 R. Lazenby and R. White: Chemosensors 6 ( 2018) 24. doi.org/10.3390/chemosensors6020024 